Article

\title{
Investigation of the Molecular Details of the Interactions of Selenoglycosides and Human Galectin-3
}

\author{
Mária Raics ${ }^{1,+}{ }^{,}$Álex Kálmán Balogh ${ }^{1,+} \oplus$, Chandan Kishor ${ }^{2,+} \oplus$, István Timári ${ }^{3}$, Francisco J. Medrano ${ }^{4}$, \\ Antonio Romero ${ }^{4}\left(\mathbb{D}\right.$, Rob Marc Go ${ }^{5}$, Helen Blanchard ${ }^{5, *} \mathbb{D}$, László Szilágyi ${ }^{3}$, Katalin E. Kövér 1,6,*(D) \\ and Krisztina Fehér ${ }^{1, *}$
}

\section{check for} updates

Citation: Raics, M.; Balogh, Á.K.; Kishor, C.; Timári, I.; Medrano, F.J.; Romero, A.; Go, R.M.; Blanchard, H.; Szilágyi, L.; E. Kövér, K.; et al. Investigation of the Molecular Details of the Interactions of Selenoglycosides and Human Galectin-3. Int. J. Mol. Sci. 2022, 23, 2494. https:// doi.org/10.3390/ijms23052494 Academic Editors: Pavla Bojarová and Vladimír Křen

Received: 12 January 2022

Accepted: 12 February 2022

Published: 24 February 2022

Publisher's Note: MDPI stays neutral with regard to jurisdictional claims in published maps and institutional affiliations.

Copyright: (C) 2022 by the authors. Licensee MDPI, Basel, Switzerland. This article is an open access article distributed under the terms and conditions of the Creative Commons Attribution (CC BY) license (https:// creativecommons.org/licenses/by/ $4.0 /)$.
1 Molecular Recognition and Interaction Research Group, Hungarian Academy of Sciences, University of Debrecen, Egyetem tér 1, H-4032 Debrecen, Hungary; raicsmaria@gmail.com (M.R.); balogh.alex@science.unideb.hu (Á.K.B.)

2 School of Chemistry and Molecular Bioscience and Molecular Horizons, University of Wollongong, Wollongong, NSW 2522, Australia; chandan@uow.edu.au

3 Department of Organic Chemistry, University of Debrecen, Egyetem tér 1, H-4032 Debrecen, Hungary; timari.istvan@science.unideb.hu (I.T.); lszilagyi@unideb.hu (L.S.)

4 Structural and Chemical Biology, Centro de Investigaciones Biológicas, Margarita Salas, CSIC Ramiro de Maeztu 9, 28040 Madrid, Spain; fjmedrano@cib.csic.es (F.J.M.); romero@cib.csic.es (A.R.)

5 Institute for Glycomics, Griffith University, Gold Coast, QLD 4222, Australia; rob.go@alumni.griffithuni.edu.au

6 Department of Inorganic and Analytical Chemistry, University of Debrecen, Egyetem tér 1, H-4032 Debrecen, Hungary

* Correspondence: h.blanchard@griffith.edu.au (H.B.); kover@science.unideb.hu (K.E.K.); feher.krisztina@science.unideb.hu (K.F.)

+ These authors contributed equally to this work.

Abstract: Human galectin-3 ( $h$ Gal-3) is involved in a variety of biological processes and is implicated in wide range of diseases. As a result, targeting $h \mathrm{Gal}-3$ for clinical applications has become an intense area of research. As a step towards the development of novel $h$ Gal-3 inhibitors, we describe a study of the binding of two Se-containing $h$ Gal-3 inhibitors, specifically that of $\operatorname{di}(\beta-D$ galactopyranosyl)selenide (SeDG), in which two galactose rings are linked by one Se atom and a $\operatorname{di}(\beta$-D-galactopyranosyl)diselenide (DSeDG) analogue with a diseleno bond between the two sugar units. The binding affinities of these derivatives to $h$ Gal- 3 were determined by ${ }^{15} \mathrm{~N}-{ }^{1} \mathrm{H}$ HSQC NMR spectroscopy and fluorescence anisotropy titrations in solution, indicating a slight decrease in the strength of interaction for SeDG compared to thiodigalactoside (TDG), a well-known inhibitor of $h$ Gal-3, while DSeDG displayed a much weaker interaction strength. NMR and FA measurements showed that both seleno derivatives bind to the canonical $S$ face site of $h \mathrm{Gal}-3$ and stack against the conserved W181 residue also confirmed by X-ray crystallography, revealing canonical properties of the interaction. The interaction with DSeDG revealed two distinct binding modes in the crystal structure which are in fast exchange on the NMR time scale in solution, explaining a weaker interaction with $h$ Gal-3 than SeDG. Using molecular dynamics simulations, we have found that energetic contributions to the binding enthalpies mainly differ in the electrostatic interactions and in polar solvation terms and are responsible for weaker binding of DSeDG compared to SeDG. Selenium-containing carbohydrate inhibitors of $h \mathrm{Gal}-3$ showing canonical binding modes offer the potential of becoming novel hydrolytically stable scaffolds for a new class of $h \mathrm{Gal}-3$ inhibitors.

Keywords: lectin; galectin-3; selenoglycosides; NMR spectroscopy; fluorescence anisotropy; X-ray crystallography; molecular dynamics

\section{Introduction}

Human galectin-3 ( $h$ Gal-3), one of the adhesion/growth-regulatory galactose-binding lectins, plays a key role in many different physiological and pathological processes, hence 
it is involved in a wide variety of diseases such as cancer, inflammation and fibrosis, heart disease and stroke [1-4]. As one of its main physiological actions, $h$ Gal-3 binds $\beta$-galactosides of glycoproteins on the cell surface, crosslinks them to form a $h \mathrm{Gal}-3$ gylcoprotein lattice $[5,6]$. This, in turn, increases the residence time of glycoproteins on the cell surface, which prolongs or enhances their activity and prevents protein-protein interactions taking place. In cancer, $h \mathrm{Gal}-3$ expression is altered and seems to be associated with tumor-specific $\mathrm{T}$ cell inactivation and NK cell activity inhibition $[7,8] . h \mathrm{Gal}-3$ is being used as a diagnostic and prognostic biomarker in cancer, heart and kidney disease [9] and drugs targeting the inhibition of $h \mathrm{Gal}-3$ are being developed to treat fibrosis [10].

Structurally, $h$ Gal-3 [11,12] is composed of two domains [13], an unstructured N terminal collagen-like region with conserved glycine/proline rich repeats that are involved in oligomerization and a C-terminal carbohydrate recognition domain (CRD) that is able to bind sugars. The CRD has a $\beta$ sandwich-like fold with two antiparallel $\beta$ sheets, one with a concave sugar binding face (S face, strands S1-S6) consisting of six $\beta$ strands (S1-S6) and a convex $\mathrm{F}$ face formed by five $\beta$-strands (F1-F5). The sugar binding site is further divided into subsites A-E, whereby subsite $C$ is the canonical $\beta$-galactoside binding site, while subsite $\mathrm{D}$ interacts with the second, neighboring sugar ring of the natural ligands. The most abundant endogenous ligand of $h \mathrm{Gal}-3, \mathrm{~N}$-acetyllactosamine (NAcLac), comprised of a galactose and N-Acetyl-glucosamine moiety is present in several $\mathrm{N}$ - and O-glycans of glycoproteins. The C-4 and C-6 hydroxyl groups and O5 ring oxygen of the galactose unit and the hydroxyl group at the $\mathrm{C}-3$ position of the N-acetyl-glucosamine residue form hydrogen bonds to the sidechain of the protein. The conserved W181 displays a $\mathrm{CH}-\pi$ stacking to the hydrophobic $\beta$ side of the galactose ring.

Due to the large potential of $h \mathrm{Gal}-3$ as a therapeutic target, a wide range of $h \mathrm{Gal}-3$ inhibitors were synthesized and evaluated $[14,15]$. While major improvements of the binding affinity was mainly achieved by the extension of the core disaccharide to reach out into other subsites, tool compounds and starting scaffolds could be obtained by isosteric substitutions in the core disaccharide, specifically via replacing the oxygen atom in the interglycosidic linkage [16]. Substitution of the oxygen with sulphur yielded a thiodigalactoside (TDG) analogue [17] of the natural ligand showing improved enzymatic/hydrolytic stability. TDG is a potent ligand for adhesion/growth-regulatory ga(lactose-binding) lectins and is used as an immunoadjuvant [18]. TDG displayed a comparable activity to the natural ligands of $h$ Gal-3 [17] and was used extensively as a starting scaffold for further derivatives [19-23]. Selenium has been incorporated into carbohydrates to assist in X-ray crystal structure determination using single/multiple wavelength anomalous diffraction techniques [24-26] and also in NMR studies [27-29]. In our previous work, we proposed replacement of sulphur by selenium in digalactosides as a further bioisosteric substitution [30]. In this report, we investigate the details of the $h$ Gal-3 binding of two seleno derivatives, SeDG and DSeDG (Scheme 1a,b, respectively). The molecular details of the recognition of the selenoglycosides by $h \mathrm{Gal}-3$ are analyzed using multiple techniques such as solution state NMR spectroscopy, fluorescence anisotropy, $X$ ray crystallography and molecular dynamics (MD) simulations.

a)

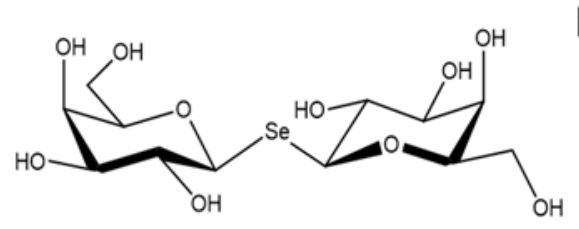

b)

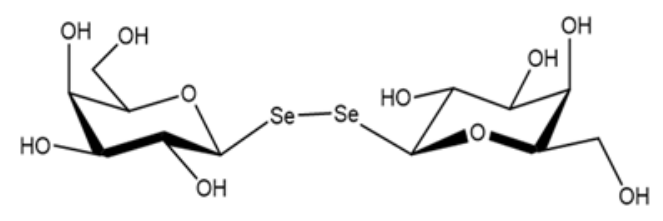

Scheme 1. Structure of the tested selenoglycosides (a) SeDG and (b) DSeDG.

\section{Results and Discussions}

2.1. Identification of the Binding Site by NMR Chemical-Shift Mapping

Chemical shift mapping via $2 \mathrm{D}^{15} \mathrm{~N}-{ }^{1} \mathrm{H}$ HSQC of ${ }^{15} \mathrm{~N}$-labeled proteins provides residuespecific information allowing mapping of the binding site(s) on the protein [31]. Chemical 
shift mapping is based on a quantitative analysis of chemical shift perturbation in protein NMR spectra, monitoring the displacements of cross peaks through a series of ${ }^{1} \mathrm{H}^{-15} \mathrm{~N}$ HSQC titration spectra. This is best suited for monitoring weak interactions in the $\mu \mathrm{M}-$ $\mathrm{mM}$ range when ligand exchange is fast between the free and bound states. In this case, the observed chemical shift is a weighted average of the chemical shifts of the free and complexed protein.

We recorded $2 \mathrm{D}^{15} \mathrm{~N}-{ }^{1} \mathrm{H}$ HSQC spectra separately on samples of $U-{ }^{15} \mathrm{~N}$-enriched CRD of $h$ Gal-3 in the presence of increasing amounts of either SeDG or DSeDG containing selenium in natural abundance [30]. An overlay of the spectra for the titration with SeDG is shown in Figure 1a with chemical shift changes plotted against the residue number depicted in Supplementary Figure S1. A shifting of some of the cross peaks on both the ${ }^{1} \mathrm{H}$ and ${ }^{15} \mathrm{~N}$ chemical shift axis was observed in the presence of the ligand without appreciable line broadening. This indicates fast ligand exchange on the NMR time scale where the observed chemical shift is a weighted average of those in the free and bound states.
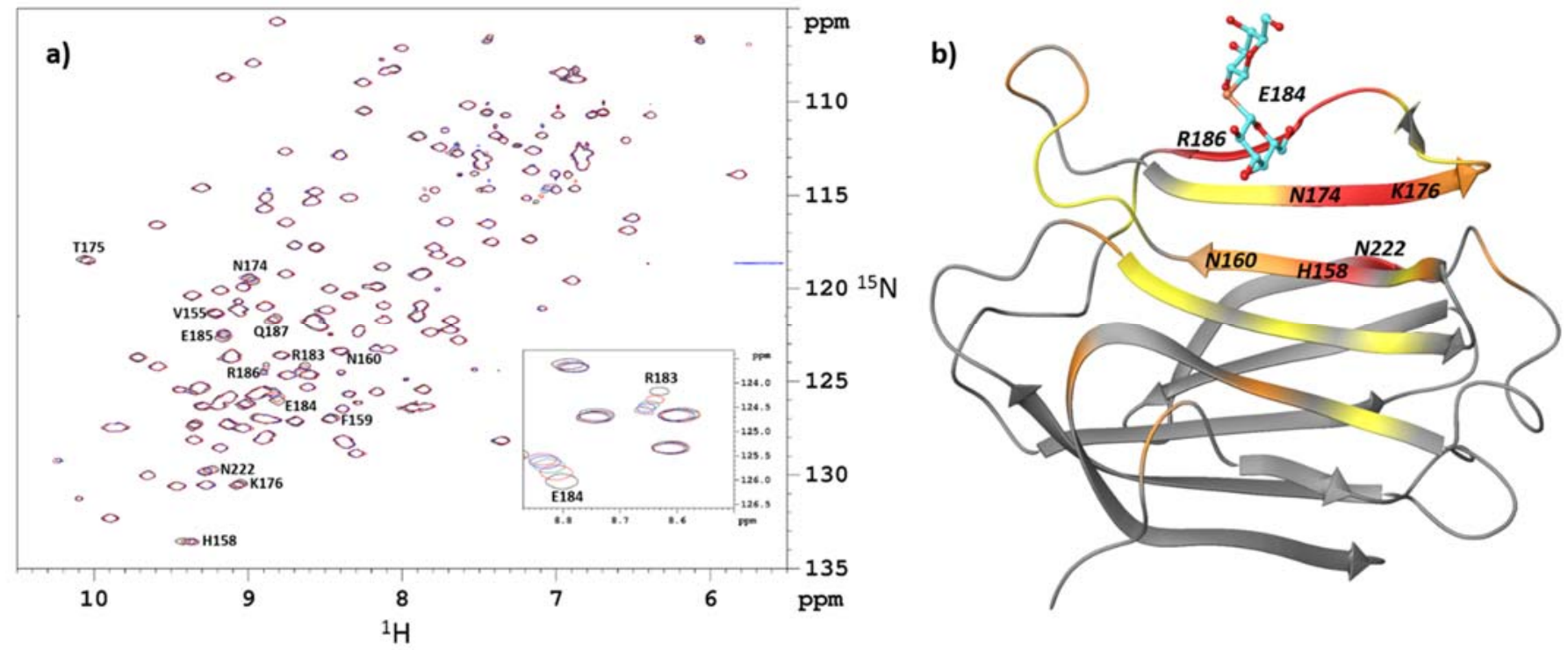

Figure 1. NMR titration of SeDG in the presence of $h$ Gal-3. (a) Overlay of $500 \mathrm{MHz} 2 \mathrm{D}^{15} \mathrm{~N}-{ }^{1} \mathrm{H} H S Q C$ spectra for $0.27 \mathrm{mM}{ }^{15} \mathrm{~N}$-labeled $h$ Gal-3 (CRD) obtained upon titration with SeDG. In the main map, cross peaks in black correspond to the reference HSQC spectrum recorded in the absence of SeDG; those in brown belong to the ${ }^{15} \mathrm{~N}-{ }^{1} \mathrm{H}$ correlation map from the last titration step $(0.4 \mathrm{mM}$ of SeDG added). The inset shows the most shifted ${ }^{15} \mathrm{~N} /{ }^{1} \mathrm{H}$ cross peaks (Arg183 and Glu184) as a function of increasing ligand concentrations (concentration of added ligand: 0.0, 0.1, 0.2, 0.3, and 0.4 mM, the corresponding cross peaks in black, red, green, blue, and brown, respectively). (b) Euclideanweighted ${ }^{15} \mathrm{~N}$ - and ${ }^{1} \mathrm{H}$ chemical shift changes [31] $(\Delta d)$ of $h$ Gal-3 (CRD) determined between the end-points of titration with SeDG. Selected characteristic $\Delta d$ values are mapped on the $\mathrm{X}$-ray structure of the $h$ Gal-3 (CRD)-SeDG complex obtained in the present study. Amino acid residues of $h \mathrm{Gal}-3$ (CRD) are color-coded as follows: $\Delta d>0.02 \mathrm{red}, \Delta d=0.01-0.02$ orange, and $\Delta d=0.006-0.01$ yellow.

Not surprisingly, when mapping the most perturbed residues onto the structure of $h$ Gal-3, we found that the chemical shifts of residues in S4 (154-165) and S5 (168-177) $\beta$-sheets near the inner (C) binding subsite are affected upon binding. Among them, His158 and Asn174 were mostly perturbed, accompanied with intermediate shifts of Thr175 and Lys176 in S5 $\beta$-strand, while Phe159 and Asn160 showed only minor changes in their $\Delta d$ $\left({ }^{15} \mathrm{~N},{ }^{1} \mathrm{H}\right)$ values (Figure $\left.1 \mathrm{~b}\right)$.

In addition, all residues between 182 and 190 were affected with the Arg183, Glu184, Glu185, Arg186 and Gln187 cross peaks shifted most significantly. These data indicate contacts of SeDG with amino acid residues in the distal ( $D$ and $E$ ) binding subsite (S6 $\beta$-strand) as well. The solution structure of the $h$ Gal-3 (CRD) complexed with SeDG should 
therefore be similar to that seen in the crystal structure or to the complex with TDG [32] occupying the canonical C/D binding region of the protein. It is to be noted, however, that "inner" and "distal" galactosyl residues (see Section 2.4) could not be distinguished in the NMR spectra because of molecular symmetry in the ligands.

For DSeDG, a similar pattern of cross peak displacements was observed in the 2D ${ }^{15} \mathrm{~N}^{-1} \mathrm{H}$ HSQC spectra of $h \mathrm{Gal}-3$ (CRD), however, with markedly reduced chemical shift changes $\left[\Delta d\left({ }^{15} \mathrm{~N},{ }^{1} \mathrm{H}\right)\right.$ (Figure S2)]. This is compatible with the crystallographic results discussed below and the $K_{d}$ values determined from ${ }^{15} \mathrm{~N}-{ }^{1} \mathrm{H}$ HSQC titrations (below).

Chemical shift perturbation was, furthermore, observed in residues far from the carbohydrate binding site. Specifically, the Asn222 cross peak was perturbed most significantly (Figure 1 and Figure S1), which is located on the F-face of the CRD. Perturbations in further F-face signals may occur but reliable detection is hampered either by small values of binding-induced chemical shifts or an overlap in the ${ }^{15} \mathrm{~N}-{ }^{1} \mathrm{H}$ HSQC spectra.

Several studies have been published [33-39] which map the carbohydrate recognition site of galectins via binding of small and high molecular weight carbohydrate ligands using $2 \mathrm{D}^{15} \mathrm{~N}-{ }^{1} \mathrm{H}$ HSQC chemical shift titration as an established NMR technique. The involvement of residues in the F-face $\beta$-sheets, in addition to those in the canonical S-face binding site, have been reported in ${ }^{15} \mathrm{~N}$ HSQC binding studies of diLacNAc [34], CD146 glycan [37] or creatine sulphate [36] to $h$ Gal-3. However, in the case of the chemical shift perturbation of Asn222 upon binding SeDG, the explanation is likely of a dynamic nature. Two different orientations were detected for the sidechain of Asn222 in the crystal structure of the SeDG- $h$ Gal-3 complex (see Section 2.4); thus, the chemical shift perturbation might be an indication of a local dynamic process taking place between the two conformational states of this residue in the complex.

\subsection{Determination of Binding Affinity by NMR Titrations}

To assess the $K_{d}$ of $h$ Gal-3 (CRD)-SeDG complex, nine residues showing the largest chemical shifts upon complex formation were selected (Figure S3a). The simultaneous fit of the binding curves yielded an equilibrium dissociation constant, $K_{d}=123 \pm 5 \mu \mathrm{M}$, indicating medium strength interaction between SeDG and $h \mathrm{Gal}-3$ (CRD).

For DSeDG ${ }^{15} \mathrm{~N}$ HSQC, the analysis indicated significantly weaker interaction in the $h$ Gal-3(CRD)-DSeDG complex. The individual fits of the binding curves (Figure S3b) for the two residues showing the highest sensitivity of chemical shifts upon titration, Thr175 and Asn174, yielded $K_{d} \mathrm{~s}$ of $11 \mathrm{mM}$ and $6 \mathrm{mM}$, respectively. The relatively large uncertainty in the $K_{d}$ values is probably due to the inherent limitation of the chemical shift mapping approach in the weak binding regime. Notably, the reliable and accurate determination of $K_{d}$ from ${ }^{15} \mathrm{~N}-\mathrm{HSQC}$ titration experiments is typically limited to the range of $10 \mathrm{mM}>K_{d}>1 \mu \mathrm{M}$, thus, the current $K_{d}$ for DSeDG is close to the upper limit of applicability of the approach.

\subsection{Determination of Binding Affinity by Fluorescence Anisotropy Titrations}

Residue W181 is known to engage in a $\mathrm{CH}-\pi$ stacking interaction with the hydrophobic $\beta$-face of the Gal ring and gives rise to an intrinsic fluorescence of the Trp residue. Fluorescence anisotropy measurements as shown in Figure 2a confirmed the presence of this specific stacking interaction for SeDG, however, no specific binding was detected for DSeDG below a ligand concentration of $0.8 \mathrm{mM}$ (Figure $2 \mathrm{~b}$ ). Above this concentration a red shift of the relative emission maximum was observed, most likely not related to any specific binding, only due to the high ligand concentration. The inset shows the intrinsic fluorescence decrease produced by the addition of the ligand to the protein solution. This decrease follows a straight line indicating the lack of specific binding. 

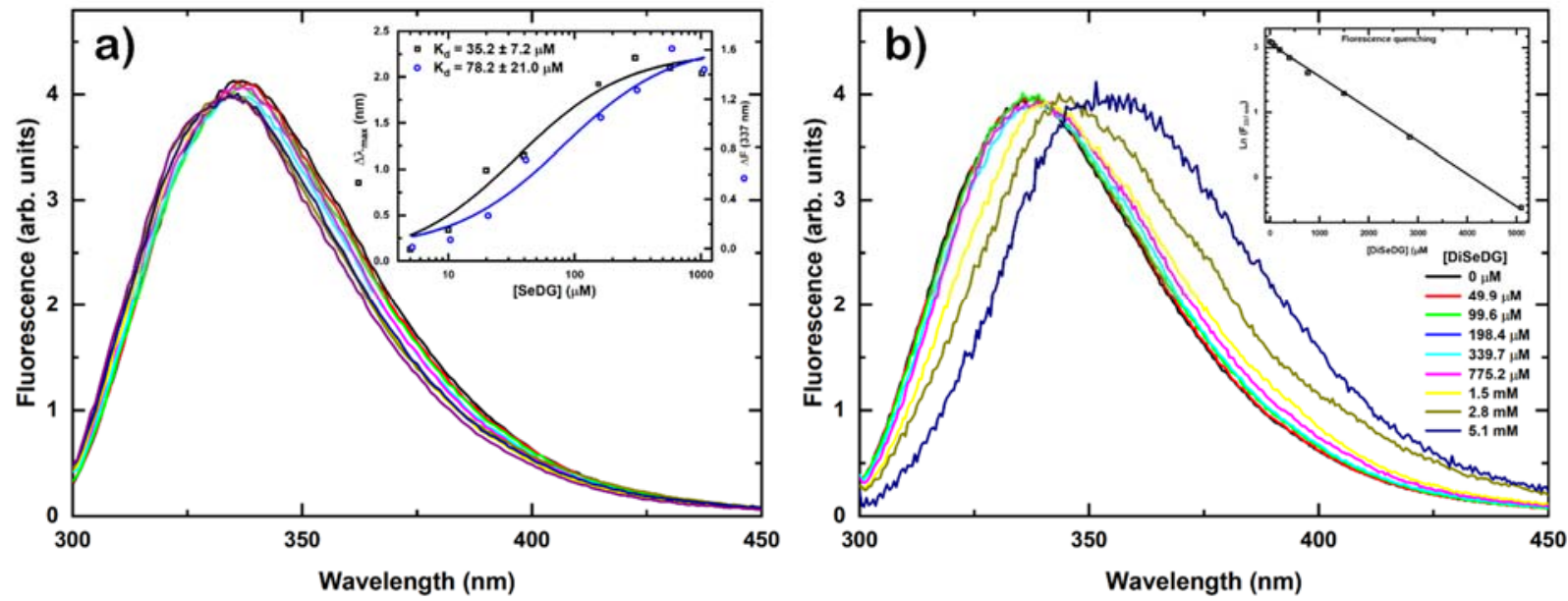

Figure 2. Fluorescence anisotropy measurements monitored by intrinsic Trp fluorescence at $25^{\circ} \mathrm{C}$. (a) Interaction of $h \mathrm{Gal}-3$ with SeDG. The inset shows the binding isotherms for increasing concentrations of SeDG at $25{ }^{\circ} \mathrm{C}$ for the blue shift of the emission maximum wavelength (black squares) and for the fluorescence intensity at $337 \mathrm{~nm}$ (blue circles). Equilibrium $K_{d}$ values were derived by data fitting to a nonlinear regression model for single site-specific binding using GraphPad Prism 8 and assuming one binding site per monomer. $K_{d}$ errors are estimates from the fitting algorithm. (b) Interaction of $h$ Gal-3 with DSeDG. The inset shows the inner filter effect produced by the addition of the ligand to the protein solution.

Furthermore, we also determined the strength of the interaction from the fluorescence anisotropy titrations and compared it to the values obtained by the NMR titrations and isothermal titration calorimetry (ITC) [40] as shown in Table 1. The dissociation constants found by NMR were $123 \pm 5 \mu \mathrm{M}$ for SeDG and $8500 \pm 2500 \mu \mathrm{M}$ for DSeDG, which were similar to the values by fluorescence anisotropy of $35.2 \pm 7.2$ for SeDG with no value available for DSeDG. These affinities were roughly in agreement with affinities of $93.1 \pm 2.6 \mu \mathrm{M}$ (SeDG) and $2800 \pm 180 \mu \mathrm{M}$ (DSeDG) [40] determined earlier by ITC measurements.

Table 1. Dissociation constants of selenoglycosides to $h$ Gal-3 measured with different methods.

\begin{tabular}{ccc}
\hline$K_{d}(\mu \mathrm{M})$ & SeDG & DSeDG \\
\hline ITC $[40]$ & $93.1 \pm 2.6$ & $2800 \pm 180$ \\
\hline Fluorescence anisotropy titration & $35.2 \pm 7.2$ & n.a. \\
\hline${ }^{15} \mathrm{~N}-{ }^{1} \mathrm{H}$ HSQC titration & $123 \pm 5.0$ & $8500 \pm 2500$ \\
\hline n.a.: no binding detected. & &
\end{tabular}

The binding strength of SeDG to $h \mathrm{Gal}-3$ is somewhat smaller than that of the sulphur analogue TDG $(67.6 \pm 2.0 \mathrm{kcal} / \mathrm{mol})$ [40], which in turn also binds somewhat less strongly than the endogenous ligand $\mathrm{N}$-acetyllactosamine $(38.6 \pm 0.5 \mathrm{kcal} / \mathrm{mol})$ [40]. Note that fluorescence anisotropy titration suggests no specific binding of DSeDG to $h$ Gal-3, indicated by not applicable (n.a.) in Table 1.

\subsection{Crystal Structures of SeDG and DSeDG in Complex with hGal-3 CRD}

Crystal structures of $h$ Gal-3 CRD with SeDG and DSeDG revealed that in both cases a galactose ring (here termed "inner" galactose ring) could bind within the carbohydrate binding site at subsite-C. A very strong peak within the CRD was revealed in the calculated anomalous difference map for the selenium atom in each of the SeDG and DSeDG structures. The Trp181 plays an important role in a stacking interaction with the inner galactose ring of both compounds. The inner galactose ring of both SeDG and DSeDG also exhibits several characteristic interactions with amino acid residues in the carbohydrate binding site. The 
C6 hydroxyl group (C6-OH) of the galactose ring participates in hydrogen bonding with the side chain of Asn174, Glu184 and a water molecule W1 (Figure 3A). The oxygen atom (O5) of the galactose ring can interact with Arg162 and water molecule W1. The C4-OH participates in hydrogen bonding with His158, Asn160, Arg162 and the water molecule W3, whilst the C3-OH interacts with two water molecules (W2 and W3). These interactions are consistent with those in the structures of galectin-3 CRD with bound galactose-based derivatives [41-43].

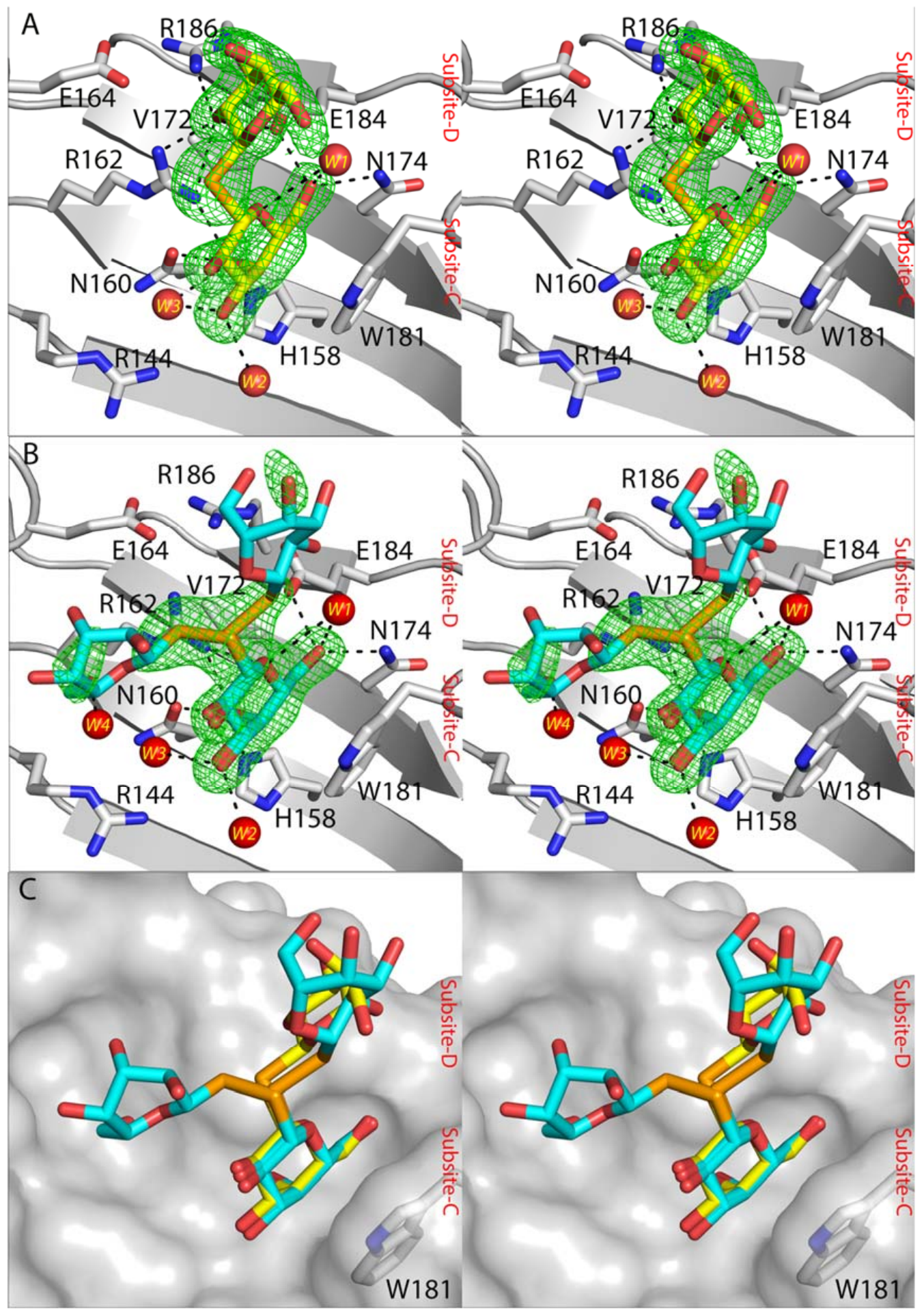

Figure 3. (A) $2\left|F_{\mathrm{O}}\right|-\left|F_{\mathrm{c}}\right| \alpha_{\mathrm{c}}$ map for SeDG (yellow colour sticks) (PDB ID 7RDP) in complex with $h$ Gal-3 CRD at $1 \sigma$. (B) DSeDG (cyan colour sticks) (PDB ID 7RDO) at $1 \sigma$ in complex with $h$ Gal-3. 
(C) Alignment of SeDG and DSeDG molecules in complex with $h$ Gal-3 CRD. $h$ Gal-3 depicted as a grey ribbon and interacting residues indicated as grey sticks, hydrogen bonds indicated as a dashed black line. The water molecules interacting with both compounds are depicted as red spheres.

The second ("distal") galactose ring of SeDG occupies subsite-D and forms fewer interactions with galectin-3 CRD. The $\mathrm{C}^{\prime}$ - $\mathrm{OH}$ of the distal galactose interacts with the side chain of Arg162, Glu184 and Arg186 of galectin-3 CRD, whilst the C3'-OH participates in hydrogen bonding with the side chain of Glu184. In contrast, the distal galactose ring of DSeDG and its Se-Se linkage show evidence of adopting two conformations (Figure 3B). One has $\sim 30 \%$ occupancy for the distal galactose ring and has its Se-Se linkage orientated toward subsite-D, and the other ( $70 \%$ occupancy) is oriented towards solvent. The electron density for DSeDG could not be unambiguously traced, however, based on the weak density associated with the distal galactose ring in the 70\% occupancy conformation there is an indication that $\mathrm{C}^{\prime}-\mathrm{OH}$ could have the ability to make a hydrogen bonding with water molecule W4 (Figure 3B).

SeDG exhibits stronger binding affinity by ca. one order of magnitude to $h \mathrm{Gal}-3$ CRD compared to DSeDG (see NMR and Section 3.5). The crystal structure of SeDG in complex with $h$ Gal-3 CRD revealed that the Se-glycosidic bond caused a bending of the distal galactose ring toward subsite-D resulting in stable interactions between $\mathrm{C}^{\prime}$ - $\mathrm{OH}$ and the side chain of Arg162, Glu184 and Arg186 of $h$ Gal-3 CRD. On the other hand, the Se-Se linkage of DSeDG is disordered and more extended within the solvent region. If the Se-Se linkage would orient the distal galactose ring towards subsite-D then there is potential for steric clashes with protein (Figure 3C). This offers an explanation for the lower affinity of the DSeDG compared to SeDG.

A comparison of the atomic structures of $h$ Gal-3 CRD SeDG complex with lactose [32] and TDG [32] indicates an identical position for the inner galactose ring for all three molecules (Figure 4D). The longer bond length in the selenium linkage in SeDG causes a slight shift of the distal galactose ring toward subsite-D compared to the glucose ring of lactose. However, the distal galactose of TDG and SeDG has an identical position in the subsite-D of galectin-3. The bond angle of C-Se-C $\left(99.9^{\circ}\right)$ is smaller than C-O-C in lactose $\left(115^{\circ}\right)$ and C-S-C $\left(101^{\circ}\right)$ in TDG (Figure 4A-C). Despite this difference in bond angle, $\mathrm{C}^{\prime}{ }^{\prime}-\mathrm{OH}$ of distal galactose ring of SeDG is still able to make hydrogen bonds with the Arg162, Glu184 and Arg186 side chains (Figure $4 \mathrm{~A}$ ). The combination of an increased C-Se bond length $1.4 \AA$ to $1.9 \AA$ and C-Se-C distance $\left(2.4 \AA\right.$ to $3.0 \AA$ ) with a reduction of the bond angle from $115^{\circ}$ to about $95^{\circ}$ lets the $\mathrm{O} 2$ in TDG and SeDG become the equivalent of $\mathrm{O} 3$ in lactose.

A

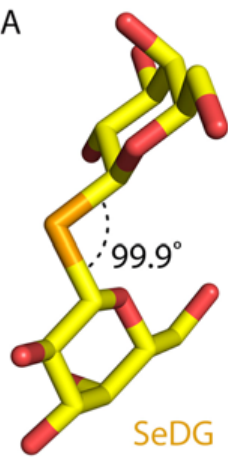

B

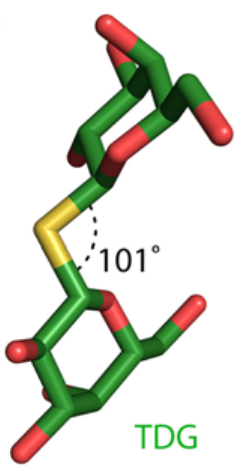

C

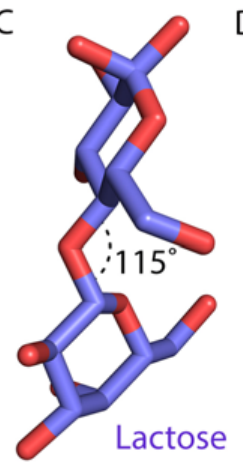

D

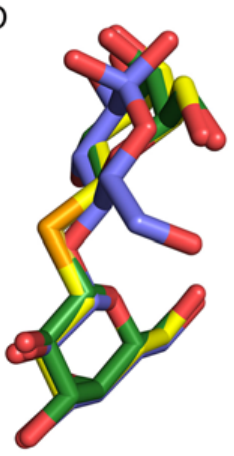

Figure 4. (A) Bond angle between C-Se-C in SeDG (yellow sticks) is $99.9^{\circ}$ (PDB ID 7RDP). (B) Bond angle between C-S-C in thiodigalactoside (TDG, green sticks) is $101^{\circ}$ (PDB ID 4JC1). (C) Bond angle between C-O-C in lactose (purple sticks) is $115^{\circ}$ (PDB ID 2NN8). (D) Superimposition of SeDG, TDG and lactose indicates an identical position for inner galactose ring for all three molecules in the carbohydrate binding site of $h \mathrm{Gal}-3$, whilst there is a slight deviation observed on SeDG distal galactose ring compared to glucose of lactose. However, the distal galactose of TDG and SeDG occupies an identical position within the $h \mathrm{Gal}-3$ carbohydrate binding site. 


\subsection{Dynamics and Energetics of the Ligand Binding by Molecular Dynamics (MD) Simulations}

Biomolecular simulations have become a method of choice to gain a detailed insight into the structure and dynamic properties of protein-ligand complexes [44-48]. To gain insight into the energetics of the selenium disaccharides binding to $h \mathrm{Gal}-3 \mathrm{CRD}$, we carried out multiple MD simulations for $1000 \mathrm{~ns}$. For DSeDG, individual simulations were performed using the two bound ligand conformations. The binding mode with $70 \%$ occupancy is designated as binding mode $\mathrm{A}$, while the one with $30 \%$ occupancy is named as binding mode $B$.

The average residence time of the ligand in the binding site was $730 \mathrm{~ns}$ for SeDG, while an average of $365 \mathrm{~ns}$ was observed for DSeDG. These residence times agree with the experimental dissociation constant of DSeDG being larger than that of SeDG. The dissociation event was tracked by the distance between the protein and the ligand as shown in representative simulations for the three complexes in Figure 5.
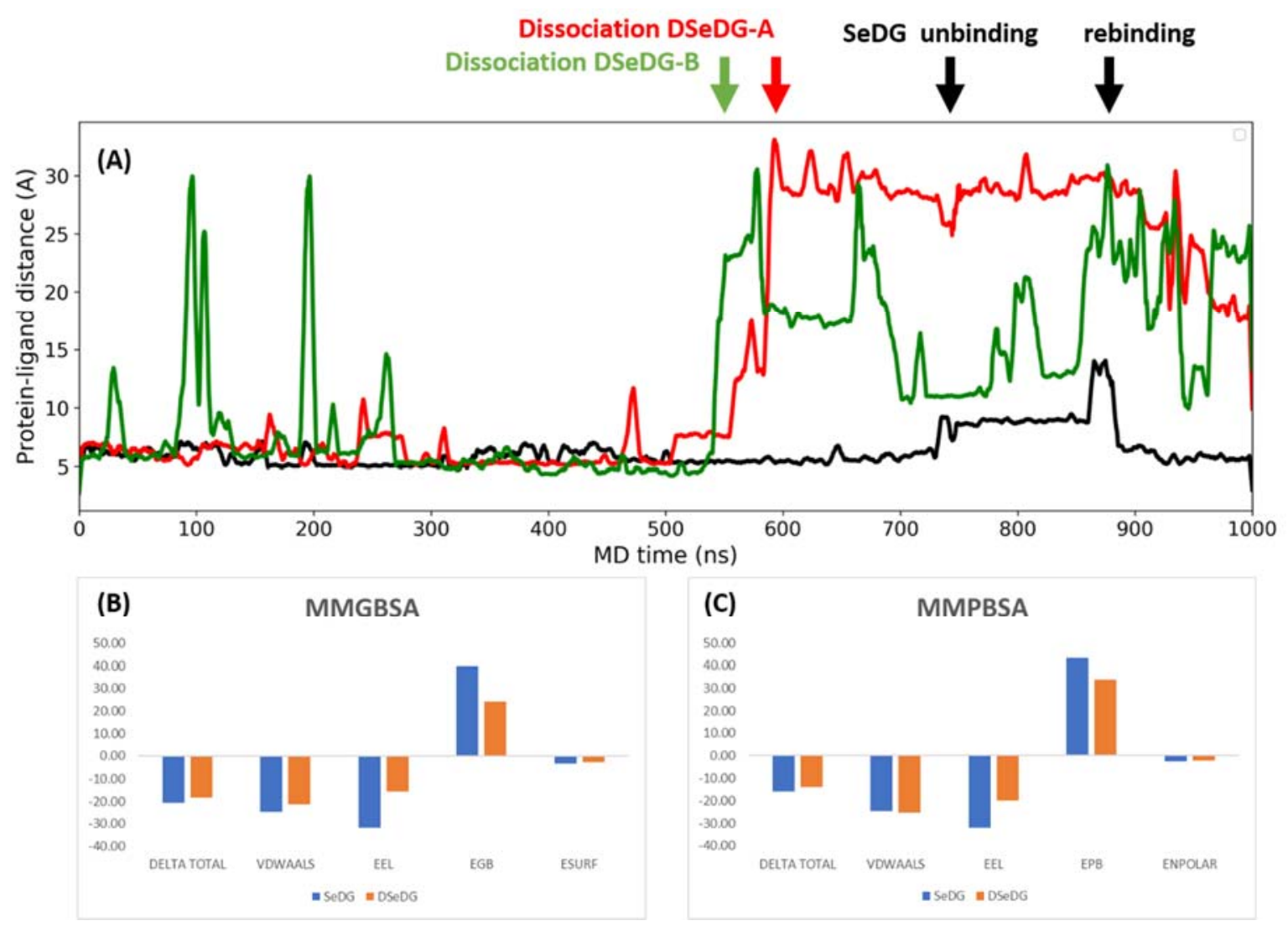

Figure 5. MD simulations started from the $h$ Gal-3 CRD complexes. (A) Evolution of the distance between the subsite $\mathrm{C}$ and the ligand as measured by the distance between geometric centre of the Trp181 ring on the protein and the centre of the interglycosidic linkage of the ligands for SeDG (black), for DSeDG starting the simulation from binding mode A (red) and binding mode B (green). (B,C) The energetic contributions of the free energy of binding for SeDG in blue and DSeDG in orange to $h$ Gal-3 CRD using the (B) MMGBSA and (C) MMPBSA calculations. The values only contain the binding enthalpy without the correction by entropic contributions to get the absolute values of free energies.

In this particular simulation, SeDG did not dissociate from $h$ Gal-3 CRD during $1 \mu \mathrm{s}$ simulation time, while in further replica simulations, dissociation did occur. Before full dissociation, multiple unbinding events were observed for DSeDG starting from binding mode B. There was no conversion between the two binding modes of DSeDG observed in the simulation time of $1 \mu \mathrm{s}$. In DSeDG, the dihedral around the diseleno bridge (C1Se-Se'-C1') started from $+90.02^{\circ}$ in binding mode A and is kept around this value in the simulation, while in binding mode B the starting dihedral is $-125.53^{\circ}$, which averages to 
$-90^{\circ}$ during the simulation (Figure S4). Thus, binding mode A corresponds to a favourable arrangement of the interglycosidic dihedral of the ligand, but in mode B that is somewhat distorted from the ideal $-90^{\circ}$ by contacts with the protein.

To quantify the strength of the association between $h \mathrm{Gal}-3 \mathrm{CRD}$ and the ligands as seen in the MD simulations, we performed MMGBSA and MMPBSA calculations [49] to obtain the free energy of the binding. The MMPB/GBSA calculations are end-state free energy methods calculating changes in energies over an ensemble of conformations obtained in simulations using implicit solvation models for estimating the solvation energy. The energy changes, however, only account for the binding enthalpy, while the entropic contribution needs to be accessed separately, but it is expected to be rather similar for analogous ligands.

The MMGBSA calculation showed a difference in the binding enthalpy between SeDG and DSeDG of $1.9 \mathrm{kcal} / \mathrm{mol}$, while the MMPBSA yielded $2.1 \mathrm{kcal} / \mathrm{mol}$ difference, which corresponds to a ca. 50-500-fold larger dissociation constant for DSeDG than for SeDG. This trend is in good agreement with the affinities found experimentally, where ITC yielded approximately 30-times and the NMR titrations gave ca. 69-times larger affinity for SeDG over DSeDG (Table 1).

We also looked at the overall energetic contributions of the calculated free energies (Figure 5B,C). For the MMGB/PBSA calculation changes in the internal energy and in the solvation energy upon ligand binding are taken into consideration. The change in internal energy is composed of changes in the internal bonding terms, the van der Waals and the electrostatic terms, while the variation in the solvation energy is accounted for by an electrostatic and a nonpolar term. The electrostatic contribution to the solvation is calculated by the linear Poisson-Boltzmann equation for each conformer or by using simplified analytical methods of the generalized Born model. The nonpolar contribution to the solvation is accounted for by an attractive dispersion and repulsive cavity interaction. This term essentially represents the creation of a cavity in the solvent and intrinsically includes entropic effects related to solvation.

The breakdown of enthalpic contributions shows favourable changes in the van der Waals and electrostatic energies, which are due to new interactions formed between the protein and the ligand at the binding site. There is, however, a huge-but expected-unfavourable change in the electrostatic contribution of the solvation, which is associated with desolvation of the protein and the ligand upon forming the complex and aligning them at the binding interface; there is also a somewhat favourable change in the nonpolar part of the solvation as calculated by the attractive dispersion and repulsive cavity terms. While the changes in the van der Waals interactions and the nonpolar solvation terms are rather similar for SeDG and DSeDG, the changes in the internal electrostatic energies and electrostatics of the solvation energy upon ligand binding are more favourable for the SeDG than for DSeDG.

Decomposition of the energetic contribution on a per residue level (Table 2) showed that similar protein residues are contributing with favourable enthalpies to the binding of SeDG as to DSeDG. The enthalpic contribution of the ligand is larger for SeDG with similar favourable van der Waals and electrostatic contribution and a large unfavourable polar solvation energy with a negligible nonpolar part as detailed in Supplementary Table S2. The strongest protein contributor residue for both compounds is Trp181 dominated by a favourable van der Waals and electrostatic interaction and an unfavourable polar solvation energy. Contact residues are also among the larger contributors, such as Asn174 dominated by large negative electrostatics, some negative van der Waals interaction and a somewhat positive polar solvation energy; His158 with equally negative van der Waals and electrostatics, but with large positive polar solvation energy; Arg162 with large negative electrostatics, somewhat negative van der Waals and large positive polar solvation energy and finally Asn160 contributing predominantly with a favourable van der Waals interaction. The van der Waals and electrostatic interactions of these contact residues are likely attributable to the hydrogen bonds formed with the ligand. Hydrophobic residues with their sidechains in contact with the ligand also contribute, such Val172, Ala146, Val155 with a negative van der Waals energy and sometimes also with a favourable polar solvation 
energy. Interestingly, while their sidechain is not much in contact with the ligand, the backbones of Cys173 and Phe159 provide negative van der Waals energies towards the binding. Glu184 and Asp148 are interesting cases, as the residues have overall positive enthalpy changes which is the result of counterbalancing a favourable change in their van der Waals and electrostatic interactions with a large unfavourable polar solvation energy. Lys176 also has an overall small positive enthalpy change, however, this is a result of an unfavourable variation in its electrostatic energy upon ligand binding. All of these protein residues also show contributions to the binding in both simulations of DSeDG, but their magnitudes are generally smaller, which adds up to a smaller overall binding enthalpy. In addition to these main interactions, numerous smaller contributions are made by residues to DSeDG as shown in Supplementary Table S2, which are not present in SeDG.

Table 2. Decomposition of enthalpic contributions of individual residues to the overall binding enthalpy sorted according to the values of SeDG.

\begin{tabular}{|c|c|c|c|c|c|c|c|c|c|}
\hline \multicolumn{5}{|c|}{ MMGBSA } & \multicolumn{5}{|c|}{ MMPBSA } \\
\hline \multicolumn{2}{|c|}{ Residue } & \multirow{3}{*}{$\begin{array}{r}\text { SeDG } \\
-10.98 \\
-295\end{array}$} & \multirow{3}{*}{$\begin{array}{c}\text { DSeDG A } \\
-7.54 \\
\mathbf{- 1 . 6 0}\end{array}$} & \multirow{3}{*}{$\begin{array}{c}\text { DSeDG B } \\
-8.84 \\
-2.06\end{array}$} & \multicolumn{2}{|c|}{ Residue } & \multirow{3}{*}{$\begin{array}{r}\text { SeDG } \\
-14.91 \\
-2.87\end{array}$} & \multirow{3}{*}{$\begin{array}{c}\text { DSeDG A } \\
-11.84 \\
\mathbf{- 1 . 2 8}\end{array}$} & \multirow{3}{*}{$\begin{array}{c}\text { DSeDG B } \\
-12.61 \\
\mathbf{- 1 . 7 0}\end{array}$} \\
\hline & & & & & & & & & \\
\hline TRP & 181 & & & & TRP & 181 & & & \\
\hline ASN & 174 & -2.30 & -0.77 & -1.15 & HIE & 158 & -1.14 & -0.46 & -0.24 \\
\hline HIE & 158 & -1.80 & -0.83 & -0.75 & ASN & 174 & -1.07 & -0.48 & -0.54 \\
\hline ARG & 162 & -1.48 & -0.42 & -0.98 & ASN & 160 & -1.01 & -0.43 & -0.63 \\
\hline ASN & 160 & -1.48 & -0.66 & -0.87 & ARG & 162 & -0.92 & -0.38 & -0.72 \\
\hline VAL & 172 & -1.04 & -0.39 & -0.52 & VAL & 172 & -0.53 & -0.25 & -0.20 \\
\hline ALA & 146 & -0.71 & -0.32 & -0.27 & ALA & 146 & -0.50 & -0.24 & -0.22 \\
\hline CYS & 173 & -0.61 & -0.11 & -0.22 & ILE & 145 & -0.31 & -0.10 & -0.14 \\
\hline ARG & 144 & -0.56 & -0.18 & -0.31 & CYS & 173 & -0.28 & -0.05 & -0.04 \\
\hline GLU & 184 & -0.36 & -0.40 & -0.12 & PHE & 159 & -0.23 & -0.07 & -0.08 \\
\hline PHE & 159 & -0.36 & -0.12 & -0.14 & GLU & 165 & -0.17 & -0.04 & -0.03 \\
\hline VAL & 155 & -0.28 & -0.28 & -0.08 & PRO & 161 & -0.17 & -0.06 & -0.09 \\
\hline ILE & 145 & -0.26 & -0.08 & -0.12 & LEU & 147 & -0.16 & -0.06 & -0.05 \\
\hline $\mathrm{ARG}$ & 183 & -0.21 & -0.23 & -0.06 & VAL & 155 & -0.14 & -0.20 & -0.06 \\
\hline SER & 237 & -0.21 & -0.03 & -0.07 & ASP & 239 & -0.13 & -0.02 & 0.05 \\
\hline LYS & 176 & 0.14 & 0.00 & 0.07 & LYS & 176 & 0.16 & 0.06 & -0.01 \\
\hline ARG & 224 & 0.15 & -0.19 & 0.10 & ASP & 148 & 0.87 & 0.58 & 0.51 \\
\hline ASP & 148 & 0.16 & -0.09 & 0.09 & GLU & 184 & 1.18 & 0.47 & 1.04 \\
\hline
\end{tabular}

\section{Materials and Methods}

\subsection{Expression and Purification of Human Galectin-3 CRD}

Human galectin-3 CRD (amino acid residues 108-250) was expressed and purified in its untagged form as described previously [32]. Briefly, two litres of bacterial culture were induced at OD600 of 0.6 with $1 \mathrm{mM}$ IPTG and grown for $3-4 \mathrm{~h}$ at $37^{\circ} \mathrm{C}$. Bacterial cells were lysed, and galectin-3 CRD was purified through affinity chromatography on a lactosyl-sepharose column. Elution was performed using $100 \mathrm{mM}$ lactose, and extensive dialysis was conducted in $1 \times$ PBS to remove lactose. Finally, the protein was concentrated to $11.9 \mathrm{mg} / \mathrm{mL}$ and flash cryo-cooled in liquid nitrogen prior to storage at minus $80^{\circ} \mathrm{C}$. 


\subsection{Sample Preparation for NMR}

For ${ }^{15} \mathrm{~N}-{ }^{1} \mathrm{H}$ HSQC titration experiments, uniformly ${ }^{15} \mathrm{~N}$-labeled human galectin-3 (CRD) was dissolved at a concentration of $0.270 \mathrm{mM}$ in potassium phosphate buffer $(10 \mathrm{mM})$ at $\mathrm{pH} 7.4$, in $90 \% \mathrm{H}_{2} \mathrm{O} / 10 \% \mathrm{D}_{2} \mathrm{O}$ solvent mixture, containing $0.5 \mathrm{M} \mathrm{NaCl}$. The ${ }^{1} \mathrm{H}$ and ${ }^{15} \mathrm{~N}$ resonance assignments for the carbohydrate recognition domain of human galectin-3 ( $h$ Gal-3 CRD) have already been reported [50] and used in the present study.

\subsection{NMR Measurements}

${ }^{15} \mathrm{~N}-{ }^{1} \mathrm{H}$ HSQC NMR spectra were recorded on a Bruker Avance II spectrometer (Bruker BioSpin $\mathrm{GmbH}$, Rheinstetten, Germany) operating at $500 \mathrm{MHz}{ }^{1} \mathrm{H}$ frequency equipped with a TXI z-gradient probe. All experiments were performed at $303 \mathrm{~K}$, and NMR data were processed with TopSpin 2.1 or 3.5 (Bruker Biospin $\mathrm{GmbH}$, Karlsruhe, Germany) and analyzed with CcpNmr Analysis V2. Gradient- and sensitivity-enhanced $2 \mathrm{D}^{15} \mathrm{~N}-{ }^{1} \mathrm{H}$ HSQC spectra were acquired with $128 t_{1}$ increments and 512 complex data points in $t_{2}$ for digitizing nitrogen and proton frequency dimensions, respectively. To obtain adequate signal-to-noise in the resulting spectra, 64 scans were acquired for each $t_{1}$ increment. Processing of raw data and analyzing (peak picking) of spectra were accomplished according to standard protocols implemented in TopSpin. For fitting of titration/binding curves, the minimization routine implemented in the Optimization Toolbox of Matlab R2015a was used. Error estimates of $K_{d}$ values were obtained by analyzing the quality of fit.

\subsection{Determination of Dissociation Constants from NMR Titration}

To quantitate binding-induced chemical shift changes, a measure $d$ (average Euclidean distance), calculated from the ${ }^{15} \mathrm{~N}\left(\delta_{N}\right)$ and ${ }^{1} \mathrm{H}\left(\delta_{H}\right)$ values, was used [31] (Equation (1)) with a scaling factor $\alpha=0.14$.

$$
d=\sqrt{\frac{1}{2}\left[\delta_{H}^{2}+\left(\alpha \cdot \delta_{N}\right)^{2}\right]}
$$

$K_{d}$ (equilibrium dissociation constant) was then calculated by numerical fitting to the following equation:

$$
\Delta d=\Delta d_{\max }\left\{\left([P]_{t}+[L]_{t}+K_{d}\right)-\left[\left([P]_{t}+[L]_{t}+K_{d}\right)^{2}-4[P]_{t}[L]_{t}\right]^{\frac{1}{2}}\right\} / 2[P]_{t}
$$

where $\Delta d$ is the change in the observed shift with reference to the free state and $\Delta d_{\max }$ is the maximum of shift change obtained on saturation with ligand (fitted also), $[P]_{t}$ and $[L]_{t}$ are total protein and ligand concentrations, respectively.

\subsection{Fluorescence Anisotropy}

Fluorescence was measured using a Fluorolog-3 (Horiba Jobin Yvon) spectrofluorometer with excitation at $295 \mathrm{~nm}$ using $5 \times 10 \mathrm{~mm}$ cells at $25^{\circ} \mathrm{C}$. Measurements were carried out at a protein concentration of $0.05 \mathrm{mg} / \mathrm{mL}$ in PBS (pH 7.0). The spectra were corrected for the buffer and ligand contribution, and for the dilution factor due to the addition of the ligand. The inner filter effect was corrected according to Mertens \& Kagi [51]. Equilibrium $K_{d}$ values were determined by fitting the data to a nonlinear regression model for one site-specific binding using GraphPad Prism 8, assuming one binding site for $h$ Gal-3. Figures were generated with ORIGIN2018 package (www.originlab.com, accessed on 11 January 2022).

\subsection{Crystallization and Structure Determination}

$h \mathrm{Gal}-3 \mathrm{CRD}$ apo crystals were grown by the vapor-diffusion hanging-drop method with $500 \mu \mathrm{L}$ reservoir solution (100 mM Tris- $\mathrm{HCl}$, $\mathrm{pH} 7.0,100 \mathrm{mM} \mathrm{MgCl}_{2}, 31 \% w / v$ PEG $6000,8 \mathrm{mM} 2$-mercaptoethanol) and $10 \mu \mathrm{L}$ drops consisting of $5 \mu \mathrm{L}$ protein solution $(11.9 \mathrm{mg} / \mathrm{mL}$ galectin-3 CRD in PBS, pH 7.4) and $5 \mu \mathrm{L}$ reservoir solution. Crystals appeared 
in 2-5 days and grew to a typical size of $0.1 \times 0.1 \times 0.5 \mathrm{~mm}$ in $1-2$ weeks. The crystals were dipped in soaking solution (reservoir solution supplemented with $35 \mathrm{mM}$ of SeDG and DSeDG) overnight (12-16 h). X-ray diffraction data sets were collected at $298 \mathrm{~K}$ at beamline MX1 of the Australian Synchrotron [52]. Data integration, scaling and merging were done using iMOSFLM and SCALA, in the CCP4 crystallographic software suite [53]. The atomic structures of the galectin-3 CRD SeDG and DSeDG complexes were solved by molecular replacement using a search model of the galectin-3 CRD (PDB ID: 2NMO [32]), and REFMAC5 was used for atomic model refinement [54]. Crystallographic data and model refinement statistics are given in Table S1. Visualization of electron densities and model building was performed using COOT [55]. Ligand geometry was obtained using the PRODRG2 server [56].

\subsection{Molecular Dynamics}

All MD simulations were performed using AMBER version 16 [57] implemented for GPUs [58,59]. The AMBER ff99SB [60] force field for the protein and the GAFF1 [61] force field for the carbohydrates with the TIP3P [62] model for water were used. Force field libraries for selenide and diselenide atom type were built with use of the R.E.D. server $[63,64]$ using Gaussian 16 [65] as the QM engine. The cut-off used for nonbonded interactions was $8 \AA$. The particle-mesh Ewald [66] procedure is used to describe long-range electrostatic interactions with a maximal grid spacing of $1 \AA$. Periodic boundary conditions were applied using a truncated octahedron geometry. The SHAKE algorithm [67] was used to keep the bond lengths of hydrogen atoms rigid allowing a time step of $2 \mathrm{fs}$ to be used. Protocol for NPT simulations: First, minimization in 2000 steps was performed, switching from steepest descent to conjugate gradient algorithm after 1000 steps. After minimization, a constant energy/constant volume (NVE ensemble) MD was carried out for 50 ps while increasing temperature from $0 \mathrm{~K}$ to $50 \mathrm{~K}$. The system was further relaxed in a $1 \mathrm{~ns}$ long MD simulation using NPT ensemble while increasing temperature from $50 \mathrm{~K}$ to $310 \mathrm{~K}$ during $500 \mathrm{ps}$ and keeping it at this temperature for $500 \mathrm{ps}$. During both relaxation steps backbone atoms were restrained with $4 \mathrm{kcal} / \mathrm{mol}^{2}$ force constant. Subsequently, a third relaxation step was conducted at $310 \mathrm{~K}$ and 1 bar pressure using an NPT ensemble for $1 \mathrm{~ns}$ without restraints. A $200 \mathrm{~ns}$ MD producing canonical NPT ensemble was carried out at $310 \mathrm{~K}$ and 1 bar. Both NTP ensembles were carried out using temperature regulation with Langevin dynamics with the collision frequency of $1 \mathrm{ps}^{-1}$ and applying isotropic pressure scaling with pressure relaxation time of 1 ps. Analysis: The 50,000 coordinate snapshots were saved for analysis in all cases. The trajectories were analyzed with cpptraj [68] and visualized in VMD [69]. The binding-free energies were calculated by using the MMPBSA.py script [70] available in AmberTools using 1000 snapshots in the calculation of the binding enthalpy. Visualization and analysis of the molecules were done in PyMOL [71].

\section{Conclusions}

We have investigated the energetics, structure and dynamics of the interaction between selenoglycosides and $h$ Gal-3 on the molecular level. Fluorescence anisotropy and ${ }^{15} \mathrm{~N}$ ${ }^{1} \mathrm{H}$ HSQC NMR titrations provided confirmatory evidence for the canonical interaction pattern by $\mathrm{C}-\mathrm{H} / \pi$-interactions and $\mathrm{H}$ bonds in solution. For SeDG, fluorescence and NMR titrations gave a $K_{d}$-value in the range of $35.2 \pm 7.2 \mu \mathrm{M}$ to $123.5 \pm 5 \mu \mathrm{M}$, and titration calorimetry provided a value of $93.1 \pm 2.6 \mu \mathrm{M}$ [40]. Analysis of the cocrystal of $h \mathrm{Gal}-3 \mathrm{CRD}$ complex with SeDG disclosed the canonical interaction pattern with galactose, as it has been described for $h$ Gal-3 and Lac(NAc) in crystallography and NMR spectroscopy $[13,72,73]$. The distal pyranose of SeDG is able to contribute hydrogen bonding between its 2-OH and Arg162, Glu184 and Arg186. This stabilization of the overall contact fully resembles interactions of TDG with toad ovary and human Gal-1 [74,75] and the CRD of $h$ Gal3 [32]. The elongation of the distance between the two Gal-units in the DSeDG is not compatible with forming an ordered structure for the second galactose moiety, explaining its low-level bioactivity [40]. The free energy of binding calculations for MD simulations 
showed a major difference between the interaction of SeDG and DSeDG with $h$ Gal-3 in the internal electrostatics as well as in the electrostatic part of the solvation. Breakdown of the binding enthalpy on a per residue level showed that overall, a similar set of residues are contributing to the binding of the two analogues, but the contributions for DSeDG are consistently smaller than for SeDG.

In summary, seleno analogues of natural ligands of $h$ Gal-3 offer a unique, new set of compounds to become versatile tools in the interaction analysis, particularly by NMR spectroscopy, $X$ crystallography or fluorescence analysis. Teaming up selenium labelling $[30,76,77]$ with substitutions at strategic sites of a glycan by ${ }^{19} \mathrm{~F}[78,79]$ offers further intriguing possibilities, via different NMR time scales due to their individual chemical shift ranges, to analyze the structures and dynamics of the glycan ligand at a new level.

Furthermore, since bioisosteric substitution of the interglycosidic oxygen by selenium atom did not significantly reduce the binding strength of monoseleno-digalactoside (SeDG) compared to the endogenous ligand, but provides resistance against hydrolytic enzymes, the seleno analogue could serve as a novel scaffold for designing further $h$ Gal-3 inhibitors. The design and synthesis of such compounds is underway in our laboratory.

Supplementary Materials: The following are available online at https:/ /www.mdpi.com/article/10 .3390/ijms23052494/s1.

Author Contributions: Conceptualization-L.S., K.E.K. and K.F.; NMR measurements and analysisM.R., I.T. and K.E.K.; FA investigations-F.J.M. and A.R.; crystallography-C.K., R.M.G. and H.B.; MD calculations and analysis-Á.K.B. and K.F.; interpretation of the data-M.R., I.T., K.E.K., F.J.M., A.R., L.S., C.K., R.M.G., H.B., Á.K.B. and K.F.; writing of the manuscript-L.S., K.E.K. and K.F.; funding acquisition-L.S., I.T., K.E.K. and K.F. All authors have read and agreed to the published version of the manuscript.

Funding: Our studies were supported by the National Research, Development and Innovation Office of Hungary (grant numbers: NN 128368 (to L.S.Z. and K.E.K.) and PD 135034 (to I.T.) and co-financed by the European Regional Development Fund (projects GINOP-2.3.3-15-2016-00004 and GINOP-2.3.2-15-2016-00008). The research of I.T. was supported by the János Bolyai Research Scholarship of the Hungarian Academy of Sciences (BO/00372/20/7) and the UNNP-21-5-DE-471 New National Excellence Program of the Ministry for Innovation and Technology from the source of the National Research, Development and Innovation Fund. K.F. acknowledges the support of the János Bolyai Research Scholarship of the Hungarian Academy of Sciences (BO/004333/18/7) and the New National Excellence Program of Debrecen University (ÚNKP-21-4-DE-165 Bolyai+). We acknowledge the Governmental Information Technology Development Agency for awarding us access to supercomputing resources based in Debrecen, Hungary.

Data Availability Statement: All data can be directly obtained by contacting the authors.

Acknowledgments: This article is dedicated to the memory of Hans-Joachim Gabius, deceased in August 2021. We are indebted to the laboratory of the late Hans-Joachim Gabius for the donation of galectin specimens used in this research.

Conflicts of Interest: The authors declare no conflict of interest.

\section{References}

1. Liu, F.-T.; Rabinovich, G.A. Galectins: Regulators of acute and chronic inflammation. Ann. N. Y. Acad. Sci. 2010, 1183, 158-182. [CrossRef] [PubMed]

2. Girotti, M.R.; Salatino, M.; Dalotto-Moreno, T.; Rabinovich, G.A. Sweetening the hallmarks of cancer: Galectins as multifunctional mediators of tumor progression. J. Exp. Med. 2019, 217, e20182041. [CrossRef] [PubMed]

3. Salatino, M.; Girotti, M.R.; Rabinovich, G.A. Glycans Pave the Way for Immunotherapy in Triple-Negative Breast Cancer. Cancer Cell 2018, 33, 155-157. [CrossRef] [PubMed]

4. Hisrich, B.V.; Young, R.B.; Sansone, A.M.; Bowens, Z.; Green, L.J.; Lessey, B.A.; Blenda, A.V. Role of Human Galectins in Inflammation and Cancers Associated with Endometriosis. Biomolecules 2020, 10, 230. [CrossRef]

5. Rabinovich, G.A.; Toscano, M.; Jackson, S.S.; Vasta, G.R. Functions of cell surface galectin-glycoprotein lattices. Curr. Opin. Struct. Biol. 2007, 17, 513-520. [CrossRef] 
6. Boscher, C.; Dennis, J.W.; Nabi, I.R. Glycosylation, galectins and cellular signaling. Curr. Opin. Cell Biol. 2011, $23,383-392$. [CrossRef]

7. Farhad, M.; Rolig, A.S.; Redmond, W.L. The role of Galectin-3 in modulating tumor growth and immunosuppression within the tumor microenvironment. Oncoimmunology 2018, 7, e1434467. [CrossRef]

8. Song, L.; Tang, J.-W.; Owusu, L.; Sun, M.-Z.; Wu, J.; Zhang, J. Galectin-3 in cancer. Clin. Chim. Acta 2014, 431, 185-191. [CrossRef]

9. Hara, A.; Niwa, M.; Noguchi, K.; Kanayama, T.; Niwa, A.; Matsuo, M.; Hatano, Y.; Tomita, H. Galectin-3 as a Next-Generation Biomarker for Detecting Early Stage of Various Diseases. Biomolecules 2020, 10, 389. [CrossRef]

10. Li, L.-C.; Li, J.; Gao, J. Functions of Galectin-3 and Its Role in Fibrotic Diseases. J. Pharmacol. Exp. Ther. 2014, 351, 336-343. [CrossRef]

11. Teichberg, V.I.; Silman, I.; Beitsch, D.D.; Resheff, G. A beta-D-galactoside binding protein from electric organ tissue of Electrophorus electricus. Proc. Natl. Acad. Sci. USA 1975, 72, 1383-1387. [CrossRef] [PubMed]

12. Sparrow, C.P.; Leffler, H.; Barondes, S.H. Multiple soluble beta-galactoside-binding lectins from human lung. J. Biol. Chem. 1987, 262, 7383-7390. [CrossRef]

13. Seetharaman, J.; Kanigsberg, A.; Slaaby, R.; Leffler, H.; Barondes, S.H.; Rini, J.M. X-ray Crystal Structure of the Human Galectin-3 Carbohydrate Recognition Domain at 2.1-Å Resolution. J. Biol. Chem. 1998, 273, 13047-13052. [CrossRef] [PubMed]

14. Blanchard, H.; Yu, X.; Collins, P.M.; Bum-Erdene, K. Galectin-3 inhibitors: A patent review (2008-present). Expert Opin. Ther. Patents 2014, 24, 1053-1065. [CrossRef]

15. Öberg, C.T.; Leffler, H.; Nilsson, U.J. Inhibition of Galectins with Small Molecules. CHIMIA Int. J. Chem. 2011, 65, 18-23. [CrossRef]

16. Szilagyi, L.; Varela, O. Non-Conventional Glycosidic Linkages: Syntheses and Structures of Thiooligosaccharides and Carbohydrates with Three-Bond Glycosidic Connections. Curr. Org. Chem. 2006, 10, 1745-1770. [CrossRef]

17. Leffler, H.; Barondes, S.H. Specificity of binding of three soluble rat lung lectins to substituted and unsubstituted mammalian beta-galactosides. J. Biol. Chem. 1986, 261, 10119-10126. [CrossRef]

18. Ito, K.; Scott, S.A.; Cutler, S.; Dong, L.; Neuzil, J.; Blanchard, H.; Ralph, S.J. Thiodigalactoside inhibits murine cancers by concurrently blocking effects of galectin-1 on immune dysregulation, angiogenesis and protection against oxidative stress. Angiogenesis 2011, 14, 293-307. [CrossRef]

19. Cumpstey, I.; Sundin, A.; Leffler, H.; Nilsson, U.J. C2-Symmetrical Thiodigalactoside Bis-Benzamido Derivatives as High-Affinity Inhibitors of Galectin-3: Efficient Lectin Inhibition through Double Arginine-Arene Interactions. Angew. Chem. Int. Ed. 2005, 44, 5110-5112. [CrossRef]

20. van Hattum, H.; Branderhorst, H.M.; Moret, E.E.; Nilsson, U.J.; Leffler, H.; Pieters, R.J. Tuning the Preference of Thiodigalactosideand Lactosamine-Based Ligands to Galectin-3 over Galectin-1. J. Med. Chem. 2013, 56, 1350-1354. [CrossRef]

21. Hsieh, T.-J.; Lin, H.-Y.; Tu, Z.; Lin, T.-C.; Wu, S.-C.; Tseng, Y.-Y.; Liu, F.-T.; Hsu, S.-T.D.; Lin, C.-H. Dual thio-digalactoside-binding modes of human galectins as the structural basis for the design of potent and selective inhibitors. Sci. Rep. 2016, 6, 29457. [CrossRef] [PubMed]

22. Peterson, K.; Kumar, R.; Stenström, O.; Verma, P.; Verma, P.R.; Håkansson, M.; Kahl-Knutsson, B.; Zetterberg, F.; Leffler, H.; Akke, M.; et al. Systematic Tuning of Fluoro-galectin-3 Interactions Provides Thiodigalactoside Derivatives with Single-Digit nM Affinity and High Selectivity. J. Med. Chem. 2018, 61, 1164-1175. [CrossRef] [PubMed]

23. Xu, L.; Hartz, R.A.; Beno, B.R.; Ghosh, K.; Shukla, J.K.; Kumar, A.; Patel, D.; Kalidindi, N.; Lemos, N.; Gautam, S.S.; et al. Synthesis, Structure-Activity Relationships, and In Vivo Evaluation of Novel Tetrahydropyran-Based Thiodisaccharide Mimics as Galectin-3 Inhibitors. J. Med. Chem. 2021, 64, 6634-6655. [CrossRef]

24. Kostlánová, N.; Mitchell, E.P.; Lortat-Jacob, H.; Oscarson, S.; Lahmann, M.; Gilboa-Garber, N.; Chambat, G.; Wimmerová, M.; Imberty, A. The fucose-binding lectin from Ralstonia solanacearum. A new type of beta-propeller architecture formed by oligomerization and interacting with fucoside, fucosyllactose, and plant xyloglucan. J. Biol. Chem. 2005, 280, 27839-27849. [CrossRef] [PubMed]

25. Shimabukuro, J.; Makyio, H.; Suzuki, T.; Nishikawa, Y.; Kawasaki, M.; Imamura, A.; Ishida, H.; Ando, H.; Kato, R.; Kiso, M. Synthesis of seleno-fucose compounds and their application to the X-ray structural determination of carbohydrate-lectin complexes using single/multi-wavelength anomalous dispersion phasing. Bioorg. Med. Chem. 2016, 25, 1132-1142. [CrossRef] [PubMed]

26. Suzuki, T.; Makyio, H.; Ando, H.; Komura, N.; Menjo, M.; Yamada, Y.; Imamura, A.; Ishida, H.; Wakatsuki, S.; Kato, R.; et al. Expanded potential of seleno-carbohydrates as a molecular tool for X-ray structural determination of a carbohydrate-protein complex with single/multi-wavelength anomalous dispersion phasing. Bioorg. Med. Chem. 2014, 22, 2090-2101. [CrossRef]

27. Uzawa, J.; Shimabukuro, J.; Suzuki, T.; Imamura, A.; Ishida, H.; Ando, H.; Yamaguchi, Y. J(77Se,1H) and J(77Se,13C) couplings of seleno-carbohydrates obtained by 77Se satellite 1D13C spectroscopy and 77Se selective HR-HMBC spectroscopy. Org. Magn. Reson. 2018, 56, 836-846. [CrossRef]

28. Timári, I.; Balla, S.; Fehér, K.; Kövér, K.E.; Szilágyi, L. ${ }^{77}$ Se-Enriched Selenoglycoside Enables Significant Enhancement in NMR Spectroscopic Monitoring of Glycan-Protein Interactions. Pharmaceutics 2022, 14, 201. [CrossRef]

29. Suzuki, T.; Hayashi, C.; Komura, N.; Tamai, R.; Uzawa, J.; Ogawa, J.; Tanaka, H.-N.; Imamura, A.; Ishida, H.; Kiso, M.; et al. Synthesis and Glycan-Protein Interaction Studies of Se-Sialosides by 77Se NMR. Org. Lett. 2019, 21, 6393-6396. [CrossRef] 
30. André, S.; Kövér, K.E.; Gabius, H.-J.; Szilágyi, L. Thio- and selenoglycosides as ligands for biomedically relevant lectins: Valencyactivity correlations for benzene-based dithiogalactoside clusters and first assessment for (di)selenodigalactosides. Bioorg. Med. Chem. Lett. 2014, 25, 931-935. [CrossRef]

31. Williamson, M.P. Using chemical shift perturbation to characterise ligand binding. Prog. Nucl. Magn. Reson. Spectrosc. 2013, 73 , 1-16. [CrossRef] [PubMed]

32. Bum-Erdene, K.; Gagarinov, I.A.; Collins, P.M.; Winger, M.; Pearson, A.G.; Wilson, J.C.; Leffler, H.; Nilsson, U.J.; Grice, I.D.; Blanchard, H. Investigation into the Feasibility of Thioditaloside as a Novel Scaffold for Galectin-3-Specific Inhibitors. ChemBioChem 2013, 14, 1331-1342. [CrossRef] [PubMed]

33. Halimi, H.; Rigato, A.; Byrne, D.; Ferracci, G.; Sebban-Kreuzer, C.; ElAntak, L.; Guerlesquin, F. Glycan Dependence of Galectin-3 Self-Association Properties. PLOS ONE 2014, 9, e111836. [CrossRef] [PubMed]

34. Ippel, H.; Miller, M.C.; Vértesy, S.; Zheng, Y.; Cañada, F.J.; Suylen, D.; Umemoto, K.; Romanò, C.; Hackeng, T.; Tai, G.; et al. Intraand intermolecular interactions of human galectin-3: Assessment by full-assignment-based NMR. Glycobiology 2016, 26, 888-903. [CrossRef]

35. Zhang, H.; Ippel, H.; Miller, M.C.; Wong, T.J.; Griffioen, A.W.; Mayo, K.H.; Pieters, R.J. Hybrid ligands with calixarene and thiodigalactoside groups: Galectin binding and cytotoxicity. Org. Chem. Front. 2019, 6, 2981-2990. [CrossRef]

36. Miller, M.C.; Cai, C.; Wichapong, K.; Bhaduri, S.; Pohl, N.L.B.; Linhardt, R.J.; Gabius, H.-J.; Mayo, K.H. Structural insight into the binding of human galectins to corneal keratan sulfate, its desulfated form and related saccharides. Sci. Rep. 2020, 10, 15708. [CrossRef]

37. Zhang, Z.Y.; Miller, M.C.; Xu, X.J.; Song, C.C.; Zhang, F.; Zheng, Y.; Zhou, Y.F.; Tai, G.H.; Mayo, K.H. NMR-based insight into galectin-3 binding to endothelial cell adhesion molecule CD146: Evidence for noncanonical interactions with the lectin's CRD beta-sandwich F-face. Glycobiology 2019, 29, 608-618. [CrossRef]

38. Miller, M.C.; Zheng, Y.; Suylen, D.; Ippel, H.; Cañada, F.J.; Berbís, M.A.; Jiménez-Barbero, J.; Tai, G.; Gabius, H.; Mayo, K.H. Targeting the CRD F-face of Human Galectin-3 and Allosterically Modulating Glycan Binding by Angiostatic PTX008 and a Structurally Optimized Derivative. ChemMedChem 2020, 16, 713-723. [CrossRef]

39. Lima, C.D.L.; Coelho, H.; Gimeno, A.; Trovão, F.; Diniz, A.; Dias, J.S.; Jiménez-Barbero, J.; Corzana, F.; Carvalho, A.L.; Cabrita, E.J.; et al. Structural Insights into the Molecular Recognition Mechanism of the Cancer and Pathogenic Epitope, LacdiNAc by Immune-Related Lectins. Chem. Eur. J. 2021, 27, 7951-7958. [CrossRef]

40. Diercks, T.; Medrano, F.J.; FitzGerald, F.G.; Beckwith, D.; Pedersen, M.J.; Reihill, M.; Ludwig, A.; Romero, A.; Oscarson, S.; Cudic, M.; et al. Galectin-Glycan Interactions: Guidelines for Monitoring by 77 Se NMR Spectroscopy, and Solvent $\left(\mathrm{H}_{2} \mathrm{O} / \mathrm{D}_{2} \mathrm{O}\right)$ Impact on Binding. Chem. Eur. J. 2020, 27, 316-325. [CrossRef]

41. Collins, P.M.; Hidari, K.I.P.J.; Blanchard, H. Slow diffusion of lactose out of galectin-3 crystals monitored by X-ray crystallography: Possible implications for ligand-exchange protocols. Acta Crystallogr. Sect. D Biol. Crystallogr. 2007, 63, 415-419. [CrossRef]

42. Dussouy, C.; Kishor, C.; Lambert, A.; Lamoureux, C.; Blanchard, H.; Grandjean, C. Linear triazole-linked pseudo oligogalactosides as scaffolds for galectin inhibitor development. Chem. Biol. Drug Des. 2020, 96, 1123-1133. [CrossRef] [PubMed]

43. Atmanene, C.; Ronin, C.; Téletchéa, S.; Gautier, F.-M.; Djedaïni-Pilard, F.; Ciesielski, F.; Vivat, V.; Grandjean, C. Biophysical and structural characterization of mono/di-arylated lactosamine derivatives interaction with human galectin-3. Biochem. Biophys. Res. Commun. 2017, 489, 281-286. [CrossRef] [PubMed]

44. Fehér, K.; Matthews, R.P.; Kövér, K.E.; Naidoo, K.J.; Szilágyi, L. Conformational preferences in diglycosyl disulfides: NMR and molecular modeling studies. Carbohydr. Res. 2011, 346, 2612-2621. [CrossRef] [PubMed]

45. Bartok, A.; Fehér, K.; Bodor, A.; Rákosi, K.; Tóth, G.K.; Kövér, K.E.; Panyi, G.; Varga, Z. An engineered scorpion toxin analogue with improved Kv1.3 selectivity displays reduced conformational flexibility. Sci. Rep. 2015, 5, 18397. [CrossRef] [PubMed]

46. Fehér, K.; Timári, I.; Rákosi, K.; Szolomájer, J.; Illyés, T.Z.; Bartok, A.; Varga, Z.; Panyi, G.; Tóth, G.K.; Kövér, K.E. Probing pattern and dynamics of disulfide bridges using synthesis and NMR of an ion channel blocker peptide toxin with multiple diselenide bonds. Chem. Sci. 2015, 7, 2666-2673. [CrossRef]

47. Zetterberg, F.R.; Peterson, K.; Johnsson, R.E.; Brimert, T.; Håkansson, M.; Logan, D.; Leffler, H.; Nilsson, U.J. Monosaccharide Derivatives with Low-Nanomolar Lectin Affinity and High Selectivity Based on Combined Fluorine-Amide, Phenyl-Arginine, Sulfur- $\pi$, and Halogen Bond Interactions. ChemMedChem 2018, 13, 133-137. [CrossRef]

48. Balogh, G.; Gyöngyösi, T.; Timári, I.; Herczeg, M.; Borbás, A.; Sadiq, S.K.; Fehér, K.; Kövér, K.E. Conformational Analysis of Heparin-Analogue Pentasaccharides by Nuclear Magnetic Resonance Spectroscopy and Molecular Dynamics Simulations. J. Chem. Inf. Model. 2021, 61, 2926-2936. [CrossRef]

49. Srinivasan, J.; Cheatham, T.E.; Cieplak, P.; Kollman, P.A.; Case, D.A. Continuum Solvent Studies of the Stability of DNA, RNA, and Phosphoramidate-DNA Helices. J. Am. Chem. Soc. 1998, 120, 9401-9409. [CrossRef]

50. Umemoto, K.; Leffler, H. Letter to the Editor: Assignment of H-1, N-15 and C-13 resonances of the carbohydrate recognition domain of human galectin-3. J. Biomol. NMR 2001, 20, 91-92. [CrossRef]

51. Mertens, M.L.; Kägi, J.H.R. A graphical correction procedure for inner filter effect in fluorescence quenching titrations. Anal. Biochem. 1979, 96, 448-455. [CrossRef] 
52. Cowieson, N.P.; Aragao, D.; Clift, M.; Ericsson, D.; Gee, C.; Harrop, S.J.; Mudie, N.; Panjikar, S.; Price, J.; Riboldi-Tunnicliffe, A.; et al. MX1: A bending-magnet crystallography beamline serving both chemical and macromolecular crystallography communities at the Australian Synchrotron. J. Synchrotron Radiat. 2015, 22, 187-190. [CrossRef] [PubMed]

53. Winn, M.D.; Ballard, C.C.; Cowtan, K.D.; Dodson, E.J.; Emsley, P.; Evans, P.R.; Keegan, R.M.; Krissinel, E.B.; Leslie, A.G.; McCoy, A.; et al. Overview of the CCP4 suite and current developments. Acta Crystallogr. Sect. D Struct. Biol. 2011, 67, 235-242. [CrossRef] [PubMed]

54. Murshudov, G.N.; Vagin, A.A.; Dodson, E.J. Refinement of Macromolecular Structures by the Maximum-Likelihood Method Acta Crystallogr. Sect. D Biol. Crystallogr. 1997, 53, 240-255. [CrossRef]

55. Emsley, P.; Lohkamp, B.; Scott, W.G.; Cowtan, K. Features and development of Coot. Acta Crystallogr. Sect. D-Biol. Crystallogr. 2010, 66, 486-501. [CrossRef]

56. Schuttelkopf, A.W.; van Aalten, D.M.F. PRODRG: A tool for high-throughput crystallography of protein-ligand complexes. Acta Crystallogr. Sect. D-Struct. Biol. 2004, 60, 1355-1363. [CrossRef]

57. Case, D.A.; Darden, T.A.; Cheatham, T.E.; Simmerling, C.L.I.; Wang, J.; Duke, R.E.; Luo, R.; Walker, R.C.; Zhang, W.; Merz, K.M.; et al. AMBER 12; University of California: San Francisco, CA, USA, 2012.

58. Le Grand, S.; Götz, A.W.; Walker, R.C. SPFP: Speed without compromise-A mixed precision model for GPU accelerated molecular dynamics simulations. Comput. Phys. Commun. 2013, 184, 374-380. [CrossRef]

59. Salomon-Ferrer, R.; Gotz, A.W.; Poole, D.; Le Grand, S.; Walker, R.C. Routine Microsecond Molecular Dynamics Simulations with AMBER on GPUs. 2. Explicit Solvent Particle Mesh Ewald. J. Chem. Theory Comput. 2013, 9, 3878-3888. [CrossRef]

60. Lindorff-Larsen, K.; Piana, S.; Palmo, K.; Maragakis, P.; Klepeis, J.L.; Dror, R.O.; Shaw, D.E. Improved side-chain torsion potentials for the Amber ff99SB protein force field. Proteins Struct. Funct. Bioinform. 2010, 78, 1950-1958. [CrossRef]

61. Wang, J.; Wolf, R.M.; Caldwell, J.W.; Kollman, P.A.; Case, D.A. Development and testing of a general amber force field. J. Comput. Chem. 2004, 25, 1157-1174. [CrossRef]

62. Jorgensen, W.L.; Chandrasekhar, J.; Madura, J.D.; Impey, R.W.; Klein, M.L. Comparison of simple potential functions for simulating liquid water. J. Chem. Phys. 1983, 79, 926-935. [CrossRef]

63. Vanquelef, E.; Simon, S.; Marquant, G.; Garcia, E.; Klimerak, G.; Delepine, J.C.; Cieplak, P.; Dupradeau, F.-Y.R.E.D. Server: A web service for deriving RESP and ESP charges and building force field libraries for new molecules and molecular fragments. Nucleic Acids Res. 2011, 39, W511-W517. [CrossRef]

64. Dupradeau, F.-Y.; Pigache, A.; Zaffran, T.; Savineau, C.; Lelong, R.; Grivel, N.; Lelong, D.; Rosanski, W.; Cieplak, P. The R.E.D tools: Advances in RESP and ESP charge derivation and force field library building. Phys. Chem. Chem. Phys. 2010, 12, 7821-7839. [CrossRef] [PubMed]

65. Frisch, M.J.; Trucks, G.W.; Schlegel, H.B.; Scuseria, G.E.; Robb, M.A.; Cheeseman, J.R.; Scalmani, G.; Barone, V.; Petersson, G.A.; Nakatsuji, H.; et al. Gaussian 16 Rev. C.01; Gaussian Inc.: Wallingford, CT, USA, 2016.

66. Darden, T.; York, D.; Pedersen, L. Particle mesh Ewald: An $N \cdot \log (N)$ method for Ewald sums in large systems. J. Chem. Phys. 1993, 98, 10089-10092. [CrossRef]

67. Miyamoto, S.; Kollman, P.A. Settle: An analytical version of the SHAKE and RATTLE algorithm for rigid water models. J. Comput. Chem. 1992, 13, 952-962. [CrossRef]

68. Roe, D.R.; Cheatham, T.E. PTRAJ and CPPTRAJ: Software for Processing and Analysis of Molecular Dynamics Trajectory Data. J. Chem. Theory Comput. 2013, 9, 3084-3095. [CrossRef]

69. Humphrey, W.; Dalke, A.; Schulten, K. VMD: Visual molecular dynamics. J. Mol. Graph. Model. 1996, 14, 33-38. [CrossRef]

70. Miller, B.R., 3rd; McGee, T.D., Jr.; Swails, J.M.; Homeyer, N.; Gohlke, H.; Roitberg, A.E. MMPBSA.py: An Efficient Program for End-State Free Energy Calculations. J. Chem. Theory Comput. 2012, 8, 3314-3321. [CrossRef]

71. Schroedinger, L. The PyMOL Molecular Graphics System; Version 1.2r3pre; Schrödinger Inc., LLC.: New York, NY, USA, 2011.

72. Umemoto, K.; Leffler, H.; Venot, A.; Valafar, A.H.; Prestegard, J.H. Conformational Differences in Liganded and Unliganded States of Galectin-3. Biochemistry 2003, 42, 3688-3695. [CrossRef]

73. Rauthu, S.R.; Shiao, T.C.; André, S.; Miller, M.C.; Madej, É.; Mayo, K.H.; Gabius, H.-J.; Roy, R. Defining the Potential of Aglycone Modifications for Affinity/Selectivity Enhancement against Medically Relevant Lectins: Synthesis, Activity Screening, and HSQC-Based NMR Analysis. ChemBioChem 2014, 16, 126-139. [CrossRef]

74. Bianchet, M.A.; Ahmed, H.; Vasta, G.R.; Amzel, L.M. Soluble beta-galactosyl-binding lectin (galectin) from toad ovary: Crystallographic studies of two protein-sugar complexes. Proteins 2000, 40, 378-388. [CrossRef]

75. Stannard, K.A.; Collins, P.M.; Ito, K.; Sullivan, E.M.; Scott, S.A.; Gabutero, E.; Grice, I.D.; Low, P.; Nilsson, U.J.; Leffler, H.; et al Galectin inhibitory disaccharides promote tumour immunity in a breast cancer model. Cancer Lett. 2010, 299, 95-110. [CrossRef] [PubMed]

76. Raics, M.; Timári, I.; Diercks, T.; Szilágyi, L.; Gabius, H.; Kövér, K.E. Selenoglycosides as Lectin Ligands: 77 Se-Edited CPMGHSQMBC NMR Spectroscopy To Monitor Biomedically Relevant Interactions. ChemBioChem 2019, 20, 1688-1692. [CrossRef] [PubMed]

77. Raics, M.; Timári, I.; Szilágyi, L.; Gabius, H.-J.; Kövér, K.E. Introducing 77Se NMR Spectroscopy to Analyzing Galectin-Ligand Interaction. In Galectins: Methods and Protocols, Methods in Molecular Biology; Stowell, S.R., Arthur, C.M., Cummings, R.D., Eds.; Springer Science+Business Media, LLC.: Berlin/Heidelberg, Germany, 2022; Volume 2442, p. 22. 
78. Martínez, J.D.; Manzano, A.I.; Calviño, E.; de Diego, A.; de Francisco, B.R.; Romanò, C.; Oscarson, S.; Millet, O.; Gabius, H.-J.; Jiménez-Barbero, J.; et al. Fluorinated Carbohydrates as Lectin Ligands: Simultaneous Screening of a Monosaccharide Library and Chemical Mapping by 19F NMR Spectroscopy. J. Org. Chem. 2020, 85, 16072-16081. [CrossRef]

79. Martínez, J.D.; Infantino, A.S.; Valverde, P.; Diercks, T.; Delgado, S.; Reichardt, N.-C.; Ardá, A.; Cañada, F.J.; Oscarson, S.; Jiménez-Barbero, J. The Interaction of Fluorinated Glycomimetics with DC-SIGN: Multiple Binding Modes Disentangled by the Combination of NMR Methods and MD Simulations. Pharmaceuticals 2020, 13, 179. [CrossRef] 